\title{
Influence of particle size distribution of conventional fine aggregate and construction demolition waste aggregate in Portland cement mortar
}

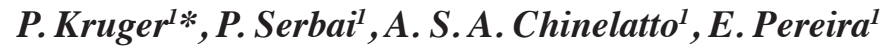 \\ ${ }^{I}$ State University of Ponta Grossa, Av. Gen. Carlos Cavalcanti 4748, 84030-900, Ponta Grossa, PR, Brazil
}

\begin{abstract}
Recycled aggregates present a varied mineralogical composition and the grading of these particulates over their particle size distribution influence the aggregate properties as well as those of the composites that they form. This study proposed a comparative investigation of the influence of the particle size distribution of fine aggregates from two different origins, namely, natural crushed stone and construction and demolition waste (CDW). Three particle size distributions were defined, so that each aggregate had its fineness modulus (FM) ranked in the granulometric ranges, following the NBR 7211 Brazilian standard. The following tests were carried out: consistency, bulk density in the fresh state, compression strength, absorption (by immersion and capillarity), dimensional and mass variation. The results showed that the aggregate mineralogical composition impacted the mortar properties and that, when analyzed along with the particle size distribution, CDW showed different and varied behavior as a function of its particle size and distribution. Another finding was that mortars produced with CDW aggregate with granulometry below the lower optimal zone $(\mathrm{FM}<2.20)$ presented reduced mechanical and physical performance. Therefore, it was concluded that CDW aggregates should not be included in the same standards as conventional aggregates regarding the fine aggregate granulometric composition.
\end{abstract}

Keywords: particle size distribution, fineness modulus, construction, and demolition waste, mortar.

\section{INTRODUCTION}

Aggregates originated from construction and demolition can be used to produce concrete and mortar. However, due to their characteristics and properties, they differ from conventional aggregates (natural and crushed) whose knowledge is already consolidated. One of the parameters that affects significantly cement composites regards the textural parameters of isolated grains in the aggregates such as grain size (expressed in terms of granulometric composition), shape, surface texture, and mineralogical composition [1]. In addition to the factors related to the characteristics of the particle system, the number of grains in each fraction and how these particles are placed in their equilibrium position have to be considered, since the particle size distribution of the system determines whether there is an increase in the packing density or not $[2,3]$. Bulk density is the aggregate property that takes particle packing into consideration. This property, added to the factors previously mentioned, also considers grain distribution (whether continuous or not), fine content (fine fraction ratio), and grain porosity (open porosity disturbs packing due to its irregular shape) [2-4]. Taking into consideration this information, for the production of more durable mortars and concretes, an aggregate with better particle packing is necessary. Such a concept must be analyzed under different perspectives when conventional aggregates or construction and demolition waste (CDW) aggregates are employed. Conventional aggregates, when extracted from the same mineral deposit,

*pkruger@uepg.br

Dhttps://orcid.org/0000-0003-4489-6462 present similar characteristics (mineralogical composition, texture, and porosity) as those from the original deposit regarding granulometric composition. On the other hand, CDW aggregates present variable characteristics, even if they originate from the same waste sampling. The different materials that constitute the waste (mortar, concrete, brick, and others) are randomly distributed in the material regarding ratio and grain size in each granulometric range.

An optimal dosage of the mixture (mortar and concrete) depends on the maximum packing density of the constituent materials since this generates a system with lower porosity, which generally promotes a lower hydration degree $[2,4]$. The hydration degree is related to the water demand, which is consequently related to the surface area and internal porosity of the grain. The larger the particle surface area and lower the packing density are, the higher the water demand is [5]. In CDW aggregates, due to the mineralogical characteristics of their grains, the water demand might be higher than that of conventional aggregates. This is caused by the fact that they tend to present higher porosity (due to the mortar adhered to the grains and ceramic materials) and larger surface area (more fragile materials that generate thinner grains in the crushing process) [6]. Another factor that influences the system packing is the volume of voids, which reduces when smaller particles occupy the spaces between larger particles, reducing the system porosity [7]. The volume of voids reduces with the increase in the percentage of fines in the mixture. However, after reaching optimum content, the fine particles start to interfere in the accommodation of larger grains, and the effect of the distance between the particles becomes preponderant, increasing the void ratio. Another scenery is when larger particles than the existing voids are inserted, they promote the appearance of new voids, 
leading to an increase in porosity and a reduction in packing efficiency [2].

Particle size distribution, along with the binder paste in the cement composites, defines the rheological properties of the fresh-state material [2, 4]. In mortar with CDW aggregates, more porous aggregates (adhered mortar and red ceramic) might compromise workability due to the higher water demand of the mixture [8]. If they are found in a higher proportion in coarser granulometric ranges, this is due to the high porosity of the grain. On the other hand, as they are more friable, they appear in large amounts as fine particulates and present a higher amount of adsorbed water due to the increase of the aggregate surface area $[9,10]$. The particle size distribution also provides the mortar a greater compressive strength, due to better grain packing [11]. The maximum strength is obtained when the matrix initial porosity is minimum, that is, the packing density is maximum $[3,4]$. When aggregates with a uniform granulometric curve are used, the composite presents higher incorporated air content and, consequently, lower strength. These aggregates also lead to lower densities of composites in the fresh and hardened states [11]. In their continuous distribution, fewer voids occur, reducing the consumption of cement paste. Granulometry and the maximum size of these aggregates also influence the drying shrinkage [12]. Regarding the composites made up of CDW aggregates, their compressive strength is also related to the distribution of the particles with lower mechanical resistance in the granulometric ranges (adhered mortar and ceramic materials) and the ratio of these materials in each range.

The objective of this investigation was to evaluate the influence of the particle size distribution of fine aggregates originated from natural stone crushing and construction and demolition waste (CDW) on the physical and mechanical properties of Portland cement mortar. Conventional aggregates show particle size distribution and classifications based on several standards. The association of cement composite performance with these aggregate classifications is also consolidated in the technical and scientific fields. Since CDW is a granular material with particular characteristics and properties, not contemplated in specifics standards, this study presents a scientific contribution for providing parameters for the classification of these aggregates from the perspective of particle size distribution, by correlating them to mortar performance.

\section{MATERIAL AND METHODS}

The experimental procedure consisted of evaluating the behavior of Portland cement mortar produced with fine aggregates of three different granulometric compositions. For each granulometric curve, two types of aggregate were studied: crushed natural stone (conventional) aggregate and construction and demolition waste (CDW) aggregate with mixed typology (Fig. 1). The mortar was prepared with one of the aggregates only, that is, there was no mixture of conventional aggregate and CDW aggregate. To each type of sand studied, $5 \%$ powdered material was added.
This percentage was elected for attending the limit of $12 \%$ recommended by the NBR 7211 standard [13] for the two types of aggregates used (crushed stone aggregates), considering the mortar protected from surface wearing. The tests were carried out with Portland cement CP II-F 32 , fine aggregate originated from diabase stone crushed in the region of Campos Gerais-PR, Brazil, and CDW fine aggregate, supplied by a concrete waste recycling company. Fig. 2 shows the granulometric curves of the aggregates investigated, located in the middle points between the lower limit usable zone (LUZ), optimum zone (upper, UOZ, and lower, LOZ, limits), and upper limit usable zone (UUZ), according to NBR 7211 standard [13]. These aggregates were named according to the fineness modulus (FM), respecting the provisions of the standard [13], as Aggregate $1 \quad(1.55<\mathrm{FM}<2.20)$, Aggregate $2 \quad(2.20<\mathrm{FM}<2.90)$, and Aggregate $3(2.90<\mathrm{FM}<3.50)$. After the definition of the composition, the characterization of the aggregates was carried out using the tests: bulk density [14], specific gravity [15], and water absorption [16]. The tests were performed in triplicate and respecting the maximum difference of results, as defined in the applicable standards.

It was used simple cement and sand to simulate the mortar constituting composite materials such as concrete. The initial trace set was 1:3:0.72 (cement: fine aggregate: water/cement ratio), in which the water/ cement $(\mathrm{w} / \mathrm{c})$ ratio was defined after the consistency tests (flow table). The Brazilian standards regarding the use of the CDW aggregate as a building material allow the use of concrete only for non-structural purposes. So, the use of a w/c ratio of 0.72 was acceptable. Since the purpose of the study was to compare the results obtained from the produced mortars, it was adopted a w/c ratio that made possible the application of these mortars, regardless of granulometric compositions and typology. Preliminary tests indicated that a lower $\mathrm{w} / \mathrm{c}$ ratio made the mortar consistency drier and the specimens did not show cohesion, which resulted in the presence of voids in the material that would compromise its performance in the hardened state. After defining the mix ratio, the remaining tests were carried out aiming at evaluating the influence of the granulometric curve and the type of aggregate in the mortar properties. The mixing procedure was according to NBR 7215 standard [17]. The focus of this study was to analyze the size classification of CDW
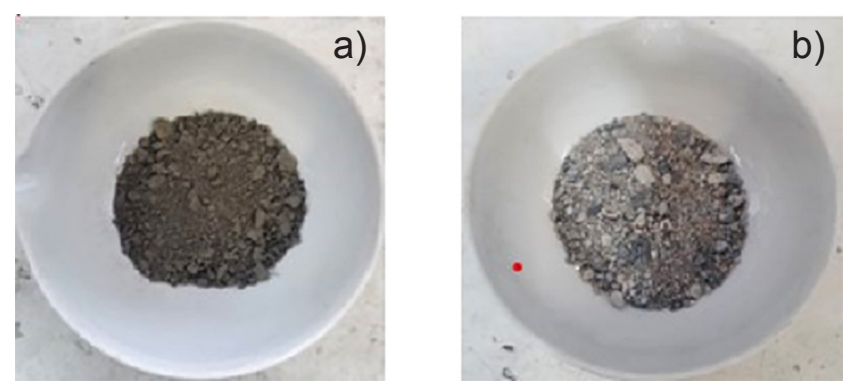

Figure 1: Images of aggregates: a) crushed natural stone (conventional); and b) construction and demolition waste (CDW). 


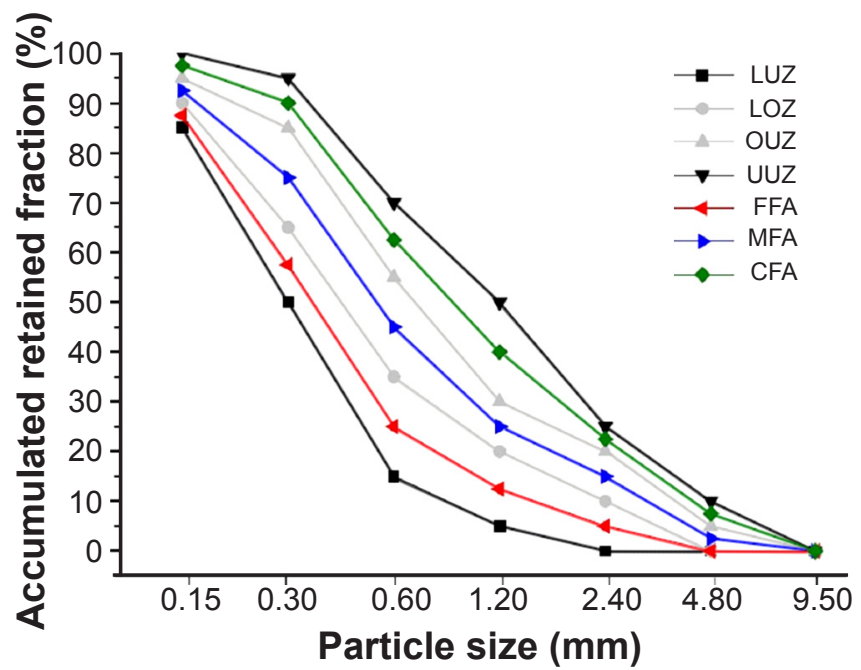

Figure 2: Particle size distribution curves according to NBR 7211 standard and studied aggregates: LUZ: lower limit usable zone; LOZ: lower limit optimum zone; UOZ: upper limit optimum zone; UUZ: upper limit usable zone; FFA: fine fine-aggregate; MFA: medium fine-aggregate; $\mathrm{CFA}$ : coarse fine-aggregate.

aggregates in the current regulations for conventional aggregates.

Five mortar samples were prepared for each test. The fresh-state tests carried out were: consistency [17] and specific gravity [18]. In the hardened state, the tests performed were: axial compression strength [17], absorption by immersion, void ratio [19], and dimensional variation [20]. For the statistical analysis of the results, analysis of variance (ANOVA) was used, complemented by the Tukey test with a 5\% significance level. The analyzes were made by comparing pairwise and not a comparison with a reference value. In all graphs, the error bars with the same letter did not differ statistically in the Tukey test at the 5\% significance level; analysis was performed by aggregate typology.

\section{RESULTS AND DISCUSSION}

Cement characterization: the results of chemical and physical characterization of the Portland CP II-F 32 cement used are shown in Table I. It is the most used cement in the region of Ponta Grossa-PR, Brazil, and had the addition of filler in its composition.

Aggregate characterization: the characterization of the conventional fine aggregates and the CDW aggregates was carried out and the curves with the composition were defined as shown in Fig. 2. To analyze the influence of the granulometric composition in the aggregate particle packing, characterization tests were also performed for the conventional and CDW aggregates (Table II). The aggregates used in this research had a distinct maximum characteristic size and fineness modulus. The objective was to evaluate the influence of particle size on the properties of the fresh and hardened state of mortar. The particle size influences the specific surface and the water adsorption on the contact surface. The Aggregate 1 had a smaller particle size, consequently a larger specific surface. The granulometric compositions of the conventional and CDW aggregates did not present a significant difference regarding specific gravity when each starting material was individually analyzed. Such a result was expected for the conventional aggregate, since its constituents had the same source and, consequently, the same density. As for the recycled aggregate, a statistical difference was observed between Aggregate 1 and Aggregate 3 , probably due to the mineralogical constitution of the particles. In larger aggregates, the probability of finding stone residue (denser material) is higher, while in smaller particles, more fragile materials such as ceramic and adhered mortar (less dense material) are more likely to be found. The recycled aggregate presented a lower specific gravity than the natural one in the three granulometric compositions. The same result was already reported by other authors [6, 21, 22].

Regarding bulkdensity, in all granulometric compositions,

Table I - Physico-chemical characteristics of Portland cement CP II-F 32.

\begin{tabular}{|c|c|c|c|c|c|c|}
\hline \multicolumn{7}{|c|}{ Chemical composition (\%) } \\
\hline Loss on ignition & $\mathrm{CaO}$ & $\mathrm{SiO}_{2}$ & $\mathrm{Al}_{2} \mathrm{O}_{3}$ & $\mathrm{SO}_{3}$ & $\mathrm{Fe}_{2} \mathrm{O}_{3}$ & $\begin{array}{l}\text { Insoluble } \\
\text { residue }\end{array}$ \\
\hline 5.9 & 59.7 & 17.2 & 4.1 & 2.7 & 2.6 & 1.4 \\
\hline \multicolumn{7}{|c|}{ Physical and mechanical characteristics } \\
\hline \multirow{2}{*}{$\begin{array}{l}\text { Specific weight } \\
\qquad\left(\mathrm{g} / \mathrm{cm}^{3}\right)\end{array}$} & \multicolumn{2}{|c|}{ Sieve residue $(\%)$} & Blaine & \multirow{2}{*}{$\begin{array}{c}\text { Water } \\
\text { demand } \\
(\%)\end{array}$} & \multicolumn{2}{|c|}{ Setting time $(\min )$} \\
\hline & \#200 (75 $\mu \mathrm{m})$ & \#325 (45 $\mu \mathrm{m})$ & $\left(\mathrm{cm}^{2} / \mathrm{g}\right)$ & & Initial & Final \\
\hline 3.08 & 3.14 & 15.69 & 3.43 & 16.0 & $4: 16$ & $5: 05$ \\
\hline \multirow{2}{*}{\multicolumn{2}{|c|}{$\begin{array}{l}\text { Soundness } \\
(\mathrm{mm})\end{array}$}} & \multicolumn{5}{|c|}{$\begin{array}{c}\text { Compressive strength } \\
(\mathrm{MPa})\end{array}$} \\
\hline & & 1 day & 3 days & 7 days & & 28 days \\
\hline \multicolumn{2}{|l|}{0.21} & 17.0 & 28.0 & 32.0 & & 38.0 \\
\hline
\end{tabular}


the conventional aggregate presented higher values than those presented by the CDW. Bulk density is a relationship between mass and volume, and when comparing the aggregates used, the aggregate specific gravity was observed to have a great influence on the bulk density $[3,7,23]$. When the two types of aggregates were compared, the lowest values of bulk density were found for Aggregate 1, that is, the composition with the highest amount of fines presented this behavior. When smaller grains are incorporated into the composition, an alteration in the particle packing occurs. The incorporated finer grains act as primary aggregates filling up the spaces between the aggregates and also the space occupied by those aggregates [24]. These finer particles are made of more fragile materials (ceramic and mortar), which in turn are materials presenting lower density than that of the natural aggregates. This indicated that the individual density of each type of aggregate influences directly the bulk density. The larger grains existing in the upper usable zone, where Aggregate 3 is placed, were responsible for the aggregate greater compactness [11]. There is a tendency towards the reduction of angularity with the increase of the grain size in crushed aggregates, which was the case of the aggregates used in this research. Such reduction in angularity increases the packing factor, that is, increases the bulk density of the aggregate [4]. This can explain the higher bulk densities of Aggregates 2 and 3. As for the recycled aggregate, the particle size distribution directly impacted the bulk density, since the higher the aggregate granulometry, the higher its bulk density was.

The CDW aggregate presented higher water absorption than the conventional aggregate for the three classifications (Fig. 3). CDW aggregates include in their composition material with a greater porosity (mortar and ceramic), which, in turn, provided higher water absorption. This behavior was observed and reported by other authors [10,22]. Regarding finer granulometry aggregates (Aggregate 1), a higher percentage of absorption was observed in both aggregates (conventional and CDW). An increase in the specific area through the insertion of finer material contributes to this behavior, which ends up providing a larger surface for the physical absorption of water molecules [5, 25]. This

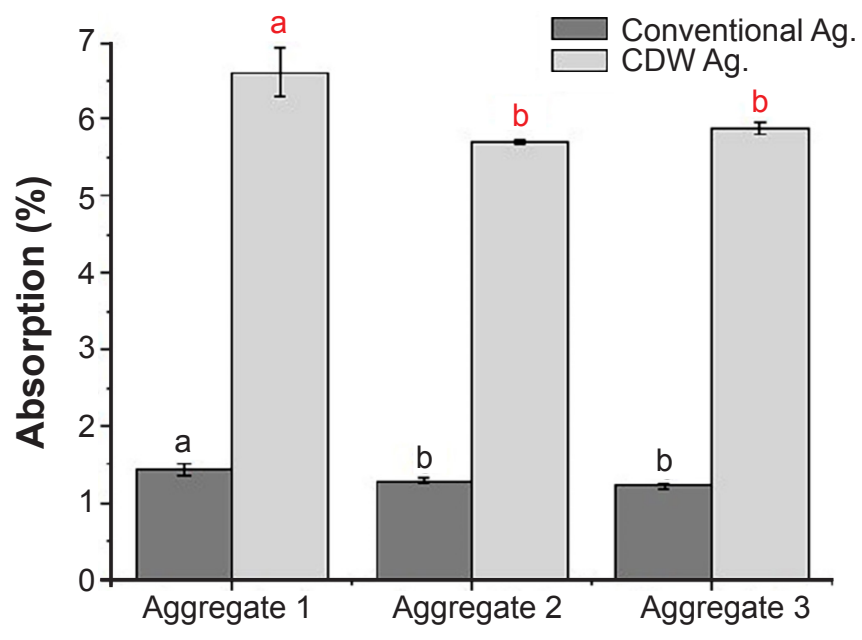

Figure 3: Water absorption of conventional and CDW aggregates.

investigation revealed that compositions with smaller granulometry showed smaller bulk density as a result of the incorporation of finer and more porous particles.

Fresh-state mortar properties: the first test carried out with mortar in the fresh state was consistency. It aimed to obtain a single water/cement ratio for the mix ratios. Due to the results obtained, a fixed mass mixing ratio was adopted, 1:3:0.72 (cement: sand: water/cement ratio) for all subsequent tests. The results of the consistency index test are presented in Fig. 4. The mortars prepared with CDW aggregate presented lower consistency indices for the three granulometric compositions when compared to the conventional aggregate. Since the void volume was smaller, the paste volume needed to fill those voids also reduced. Thus, there was more paste to surround the grains, reducing internal friction between the particles and increasing the flow [4]. As verified in the characterization of the aggregates, the granulometric composition that had a greater amount of fine particles (Aggregate 1) showed a larger specific area, providing a larger adsorption surface [5, 25]. Therefore, when the water amount was kept constant, compositions with smaller granulometry tended to have a greater impact on workability, reducing the flow.

Table II - Physical characteristics of conventional and CDW aggregates.

\begin{tabular}{ccccccc}
\hline Aggregate & $\begin{array}{c}\text { Characteristic } \\
\text { maximum size } \\
(\mathrm{mm})\end{array}$ & $\begin{array}{c}\text { Fineness } \\
\text { modulus }\end{array}$ & $\begin{array}{c}\text { Bulk density } \\
\left(\mathrm{g} / \mathrm{cm}^{3}\right)\end{array}$ & $\begin{array}{c}\text { Specific } \\
\text { gravity } \\
\left(\mathrm{g} / \mathrm{cm}^{3}\right)\end{array}$ & $\begin{array}{c}\text { Absorption } \\
(\%)\end{array}$ \\
\hline \multirow{3}{*}{ Conventional } & 1 & 2.4 & 1.88 & $1.75^{\mathrm{a}}$ & $2.90^{\mathrm{a}}$ & $1.43^{\mathrm{a}}$ \\
& 2 & 4.8 & 2.55 & $1.82^{\mathrm{b}}$ & $2.89^{\mathrm{a}}$ & $1.29^{\mathrm{b}}$ \\
& 3 & 6.3 & 3.20 & $1.81^{\mathrm{b}}$ & $2.90^{\mathrm{a}}$ & $1.24^{\mathrm{b}}$ \\
\hline \multirow{3}{*}{ CDW } & 1 & 2.4 & 1.88 & $1.35^{\mathrm{a}}$ & $2.46^{\mathrm{a}}$ & $6.61^{\mathrm{a}}$ \\
& 2 & 4.8 & 2.55 & $1.40^{\mathrm{b}}$ & $2.48^{\mathrm{a}}$ & $5.71^{\mathrm{b}}$ \\
& 3 & 6.3 & 3.20 & $1.46^{\mathrm{b}}$ & $2.49^{\mathrm{a}}$ & $5.88^{\mathrm{b}}$ \\
\hline
\end{tabular}

Note: for each type of aggregate (conventional or CDW), means followed by the same letter in the column do not differ statistically in the Tukey test at the $5 \%$ significance level. 


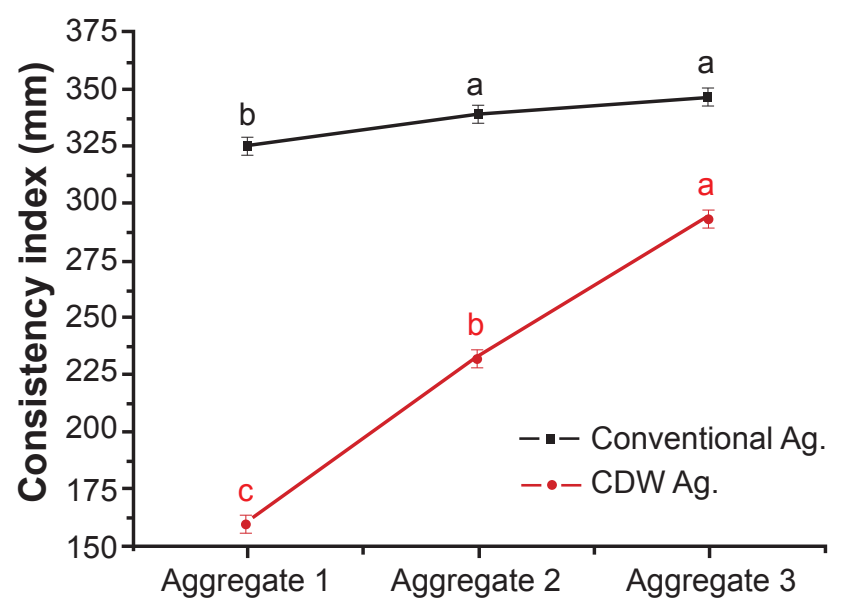

Figure 4: Consistency index of the mortars.

Fig. 5 presents the images of mortar with 0.72 water/ cement ratio with $\mathrm{CDW}$ and conventional aggregates after the consistency test, carried out in the flow table. The mortar samples prepared with CDW presented lower density in the fresh state than those prepared with conventional aggregate (Fig. 6). Similar results were verified by other authors [24-26]. This behavior occurs because the density of recycled aggregates is lower than that of the conventional aggregates, which affects the mortar characteristics [23]. The results obtained in this test followed the trend observed in the specific gravity and bulk density of the aggregates. Lower results were obtained for the mortar prepared with Aggregate 1, due to the greater amount of fines used, influencing the bulk density result obtained in the aggregate characterization.

Hardened state mortar properties: the results of the absorption by immersion and void ratio tests for mortars prepared with conventional and recycled aggregates are shown in Fig. 7. The mortars prepared with CDW presented higher absorption by immersion than the ones prepared with conventional aggregate, for all granulometric curves. Similar results were verified by other authors [27-29]. Since

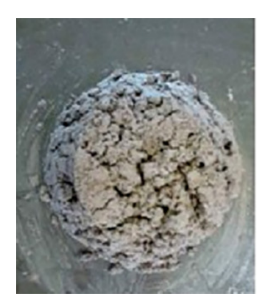

a)

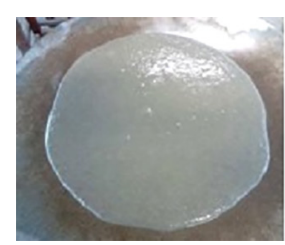

d)

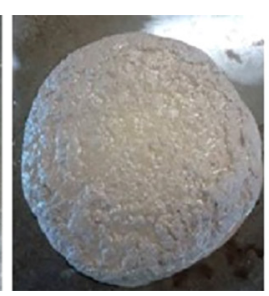

b)

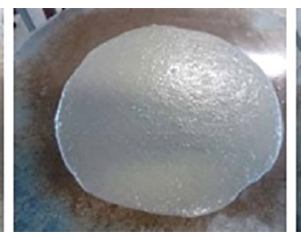

e)

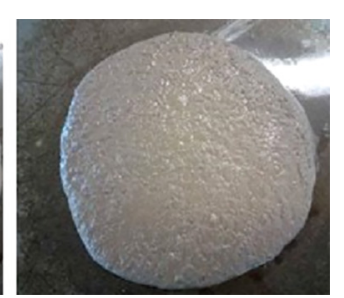

c)

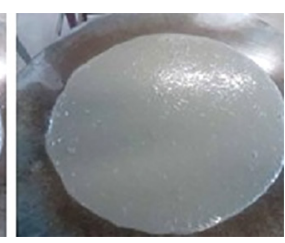

f)
Figure 5: Images of mortars with CDW (a-c) and conventional (d-f) aggregates after the consistency index test prepared with Aggregate 1 (a,d), Aggregate 2 (b,e), and Aggregate 3 (c,f).

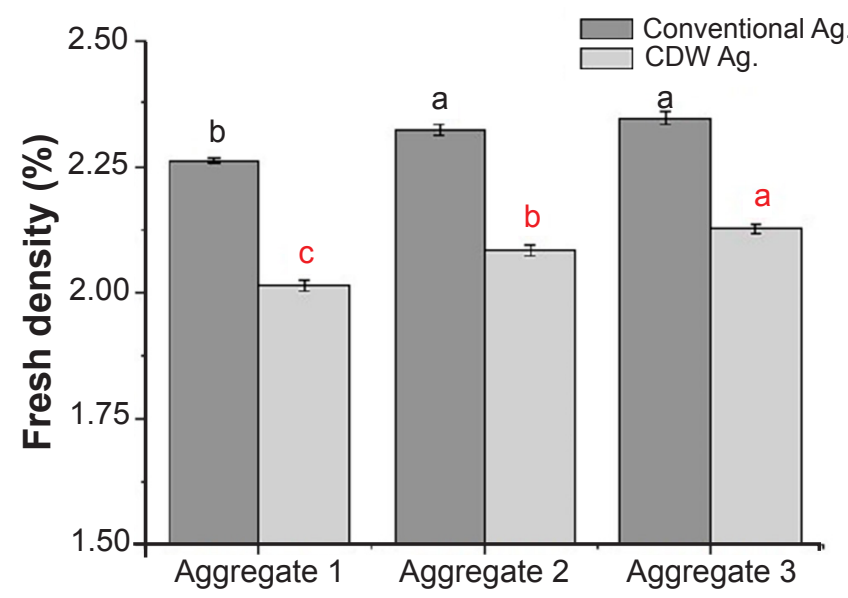

Figure 6: Fresh density of the mortars.

recycled aggregates are more porous, this characteristic affects the properties of the mortar prepared with this type of aggregate, increasing the material absorption. Such a characteristic can be confirmed by the void ratio, which was higher in the CDW mortar. Two factors promoted greater absorption in CDW mortars: higher absorption of recycled aggregates and lower compactness of the mortar prepared with this type of aggregate, due to the lower bulk density of the CDW aggregate [27-29].

The mortars prepared with conventional Aggregate 1 presented higher absorption by immersion when compared to the other mortars produced with conventional aggregate. Although it did not present a void ratio different from the mortar produced with Aggregate 2, considering the high standard deviation found, the equivalence between the void ratio observed might not be reliable. The higher absorption observed in the mortar with conventional Aggregate 1 probably occurred due to the bulk density presented by the aggregate. Therefore, the cement paste might have been insufficient to fill the existing voids between the sand grains, increasing the mortar volume that could be filled with water. When the recycled aggregate was investigated, the mortar produced with Aggregate 1 presented higher absorption by immersion, probably due to the presence of materials that presented high absorption, such as ceramic and mortar residue. This mortar presented quite dry consistency, hampering the process of molding the samples and impacting the void ratio. Another factor that might have influenced this result was the lower unitary mass of this granulometric composition, which indicated the existence of more voids. The cement paste available might have been insufficient to fill them, resulting in the higher void ratio of the mortar and consequent absorption increase. The mortar prepared with Aggregate 3 presented the best performance, probably due to the greater packing, resulting in the mortar with the lowest void ratio. Besides, this aggregate may have a larger amount of concrete or rock particles, due to the existence of larger particles. The aggregate of concrete and/or rock absorbs less water reflecting this characteristic in the mortars [22].

The results obtained from the dimensional variation and the mass variation tests of the mortars prepared with conventional 
a)

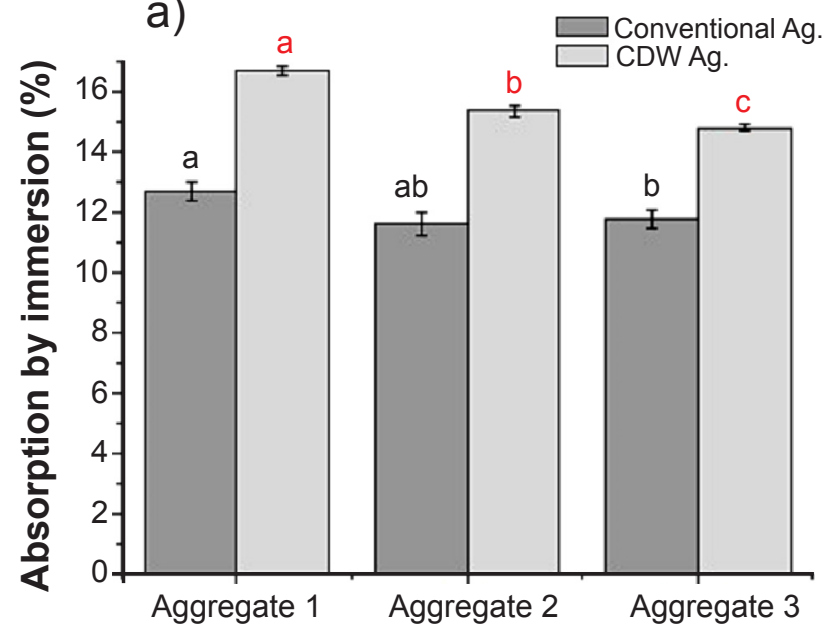

b)

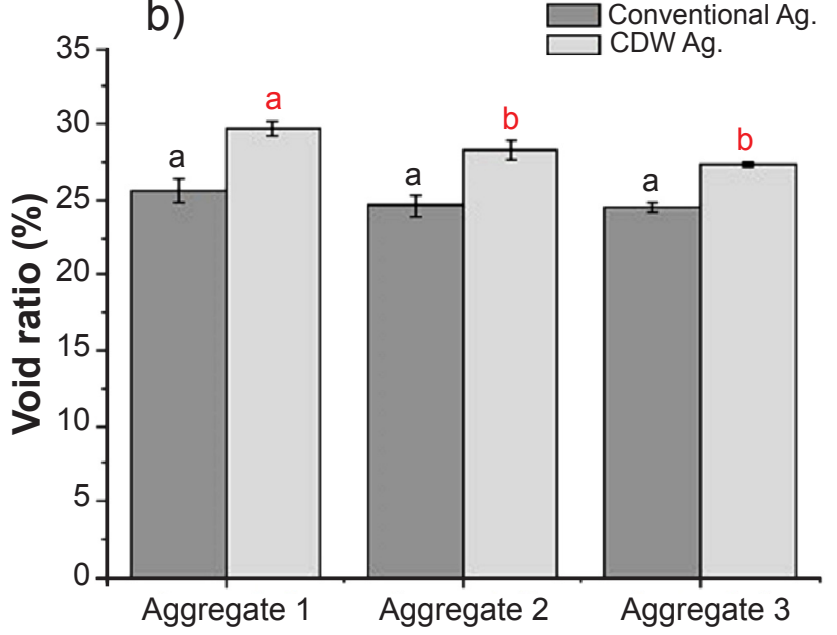

Figure 7: Absorption by immersion (a) and void ratio (b) of the mortars.

and CDW aggregates, at 28 days of curing, are presented in Fig. 8. All mortar samples presented size and mass variation at 28 days of curing. The amount of water added to the mortar directly influences the drying shrinkage [22, 27]. Although all the mortars investigated presented the same water/cement ratio, in the case of mortar prepared with conventional aggregate, bleeding was observed in the three granulometric compositions, which reduced the amount of effective water in the mixture. Since the mortar prepared with the Aggregate 1 presented higher absorption than the other samples, this characteristic might have influenced the reduction in the effective water/cement ratio and, consequently, the reduced retraction. Besides, the air content incorporated in the mortar produced with Aggregate 1 might have contributed to the reduction in retraction, since aggregates with lower bulk density tend to incorporate more air in the mortar [4]. This air amount might reduce retraction since it prevents the paste from occupying these spaces. The mortar with CDW aggregate showed a different dimensional variation behavior. The amount of adhered mortar and ceramic residues increased the dimensional retraction due to the greater absorption of aggregate that provoked a fast loss of the water utilized in the mortar mix [22, 30]. Since Aggregate 1 presented the greatest amount of fines, this aggregate showed a greater tendency to contain mortar and ceramic residues among its constituent materials [9], thus justifying its behavior. As Aggregate 3 presented larger grains, it might contain large amounts of less porous material in its composition, which might justify the lower retraction of its mortar [22]. The mortar prepared with CDW also presented higher mass loss in all granulometric curves, which was in agreement with the higher dimensional retractions observed in the mortar with this type of aggregate [22].

The results obtained in compression strength tests of mortars prepared with conventional and CDW aggregates are presented in Fig. 9. Regarding the conventional aggregate, the mortar prepared with Aggregate 1 presented a different behavior from that of the mortar with different granulometry. Aggregates with lower bulk density tend to incorporate more air in the mortar [4]. This might explain the lower compression strength presented by the mortar prepared with conventional Aggregate 1 since this aggregate was the one presenting the lowest bulk density.
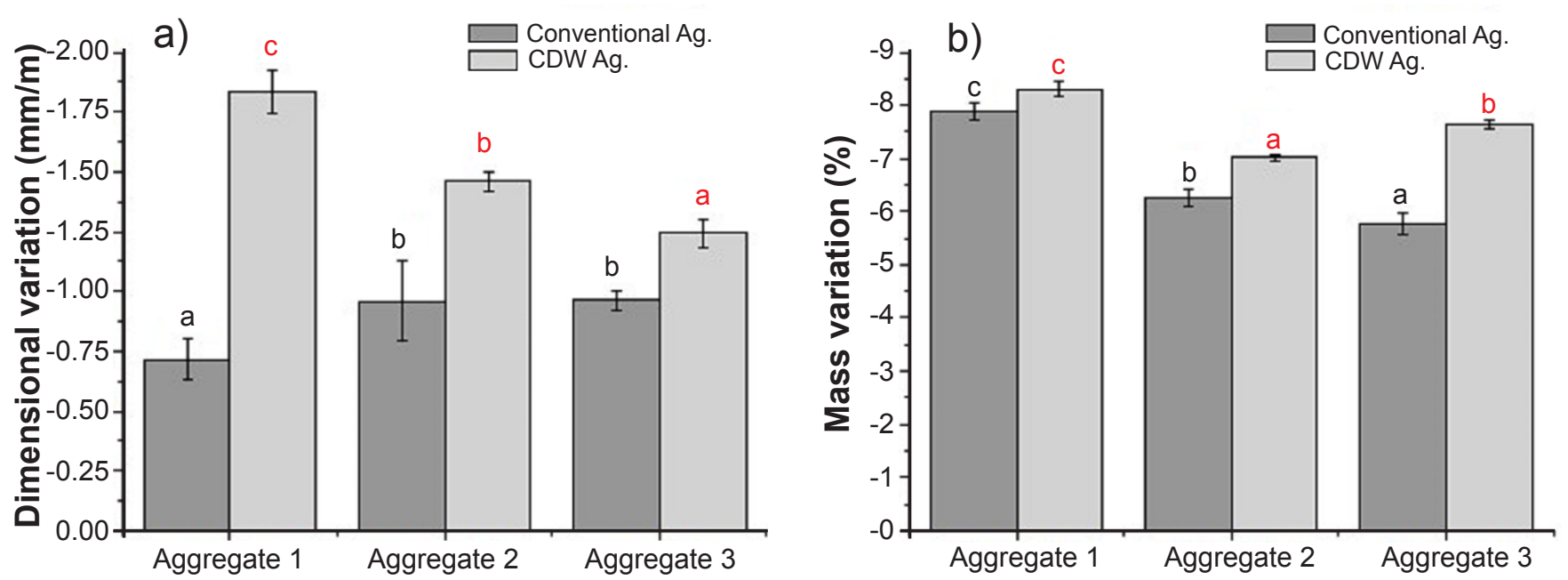

Figure 8: Dimensional (a) and mass (b) variations at 28 days of curing of the mortars. 


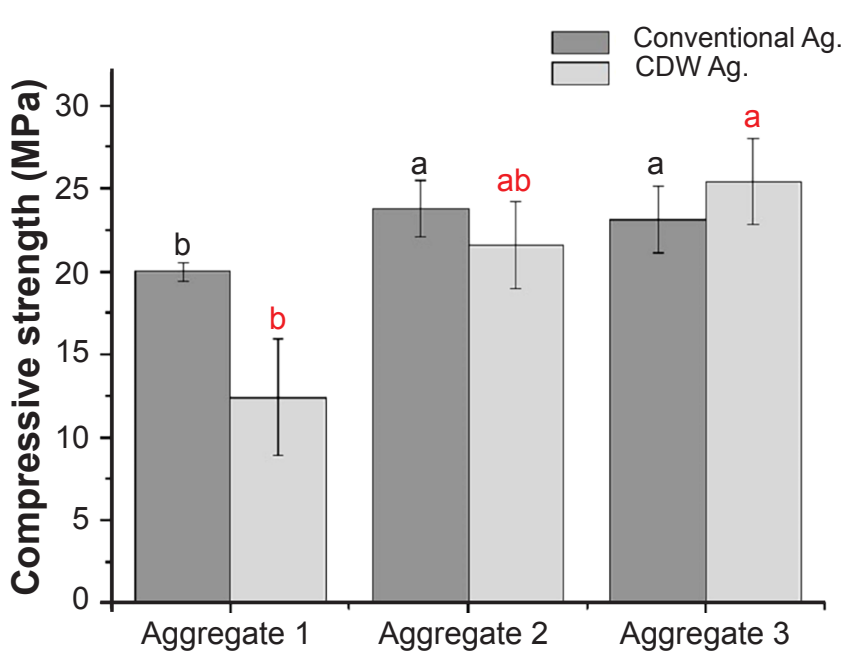

Figure 9: Compressive strength of the mortars.

This occurred because the incorporated air was present in the binder paste [12]. Since aggregates with smaller specific gravity need a greater volume of paste to fill the voids, the incorporated air content was higher. Also, the higher void ratio in this mortar, when compared to the other mortars prepared with conventional aggregate, confirmed the higher porosity of the material and its consequent resistance loss. Another difference found regarding the mortar compression strength was when Aggregate 1 was used with different mineralogical compositions. The aggregate with smaller granulometry showed smaller particles in its composition, while in CDW aggregates, the particles might be made of more fragile and porous materials, such as ceramic and adhered mortar $[9,31,32]$. The consistency test revealed that the mortar produced with CDW Aggregate 1 presented a loss of workability and cohesion. This behavior may have interfered in the molding process of the specimens and influenced their strength results. More porous aggregates are likely to have absorbed the mixture water, affecting its cohesion and making the mortar more susceptible to cracks, thus reducing the mortar compression strength. In the mortars prepared with Aggregates 2 and 3 of the two types of aggregates (conventional and CDW), no significant differences were seen in the compression strength results. This behavior might result from a combination of two factors, better particle packing in these aggregates and the amount of water available for the mortar mixture. The mortars prepared with conventional aggregate presented an excess of free water, leading to bleeding. Such water excess reduced its compression strength.

Table III shows a summary of the properties studied. The conventional and CDW aggregates presented different behavior when their distinct granulometries were analyzed. In general, mortars produced with conventional aggregates presented better performance regarding the investigated properties when compared to the mortars prepared with CDW. Such scenery was already reported in previous studies, emphasizing that depending on the property under analysis, the best performance is achieved for a specific type of granulometry (e.g. dimensional variation and mass). However, granulometry seemed not to influence other properties, which presented similar results (e.g. workability loss, absorption, void index, compression strength). On the other hand, when the mortar produced with CDW was analyzed, the granulometry was an influencing factor. The mortars produced with finer CDW aggregates tended to show the worst performance in all properties investigated. When the compression strength property was analyzed, the mortar produced with medium and coarse aggregates presented resistance similar to that of the conventional aggregates. These results suggested that CDW aggregates require specific regulations guiding their use, in which the classifications already established for the conventional aggregates need a new approach. This research showed that CDW aggregates, classified as fine aggregates, with their fineness modulus within the limits defined in the Brazilian regulation for conventional aggregates, did not present suitable performance to be used in the production of mortar.

Table III - Summary of properties in relation to the studied aggregates.

\begin{tabular}{|c|c|c|c|c|c|c|}
\hline \multirow{2}{*}{ Property } & \multicolumn{3}{|c|}{ Conventional } & \multicolumn{3}{|c|}{ CDW } \\
\hline & Aggregate 1 & Aggregate 2 & Aggregate 3 & Aggregate 1 & Aggregate 2 & Aggregate 3 \\
\hline $\begin{array}{c}\text { Loss of } \\
\text { workability }\end{array}$ & & - & + & & + & \\
\hline $\begin{array}{l}\text { Absorption by } \\
\text { immersion }\end{array}$ & & - & + & & + & \\
\hline Void ratio & + & - & + & & + & \\
\hline $\begin{array}{l}\text { Dimensional } \\
\text { variation }\end{array}$ & + & - & & & & \\
\hline Mass variation & & - & & & + & \\
\hline $\begin{array}{l}\text { Compressive } \\
\text { strength }\end{array}$ & & - & + & + & + & + \\
\hline
\end{tabular}

'-' and '+': aggregate that suffered the greatest negative and positive influence, respectively, on the analyzed property. 


\section{CONCLUSIONS}

This study evaluated the behavior of mortars prepared with different granulometric compositions of construction and demolition waste (CDW) aggregate, comparing its results with those obtained for mortars prepared with conventional aggregate in the same granulometric compositions. The mortars prepared with CDW presented worse performance than those presented by the mortars produced with conventional aggregate. In the fresh state, the mortar produced with CDW showed workability loss and bulk density reduction when compared to the mortar produced with conventional aggregate. When the CDW aggregate was used, its particle size distribution had great interference in workability and the mortar produced with aggregate below the lower optimal zone (fineness modulus, $\mathrm{FM}<2.20)$ showed lower bulk density. In the hardened state, the mortars produced with CDW obtained less satisfactory performance than those produced with conventional material, since they presented higher absorption by immersion, higher void ratio, higher dimensional and mass variations, and lower strength. In general, the particle size distribution of aggregates and their mineralogical composition were observed to influence the performance of the mortar properties, and the finest granulometry aggregates, found below the lower optimal zone $(\mathrm{FM}<2.20)$, presented lower physical and mechanical performance. Finally, our results led to the conclusion that the Brazilian regulation for conventional aggregates does not apply satisfactorily to CDW aggregates. We believe that further discussion is needed and maybe a new approach to the specific classification of recycled aggregates, and their granulometric compositions, should be adopted.

\section{REFERENCES}

[1] P. Petrounias, P. Giannakopoulou, A. Rogkala, P.M. Stamatis, P. Lampropoulou, B. Tsikouras, K. Hatzipanagiotou, Minerals 8, 12 (2018) 1.

[2] J.T.M. Francisco, A.E. de Souza, S.R. Teixeira, Cerâmica 65, Suppl.1 (2019) 22.

[3] C.R. Correa, C.H. Pereira, J.H.S. Rêgo, Amb. Constr. 20, 4 (2020) 305.

[4] H. Carasek, R.C. Araújo, O. Cascudo, R. Angelim, Matéria 21 (2016) 714.

[5] A.M. Betioli, M. Fortunato, B.R. Martins, J.M. Casali, J.C. Rocha, G. Collodetti, Amb. Constr. 20, 3 (2020) 385.

[6] C. Rodríguez, C. Parra, G. Casado, I. Miñano, F. Albaladejo, F. Benito, I. Sanchez, J. Clean. Prod. 20 (2016) 152.

[7] H.M.T. Lopes, A.C.C. Peçanha, A.L. de Castro, Matéria 25, 1 (2020) 1.

[8] A. Katz, D. Kulisch, Mater. Struct. 50 (2017) 1.

[9] D. Almeida e Silva, C.E. Luna de Melo, Paranoá 26
(2020) 36 .

[10] F. Agrela, M.S. De Juan, J. Ayuso, V.L. Geraldes, J.R. Jiménez, Constr. Build. Mater. 25 (2011) 3950.

[11] C. Londero, L.A. Lenz, Í.M.R. dos Santos, N.S. Klein, Cerâmica 63, 365 (2017) 22.

[12] P.K. Mehta, P.J.M. Monteiro, Concreto: microestrutura, propriedades e materiais, $3^{\text {rd }}$ ed., Ibracon, S. Paulo (2008) 1.

[13] NBR 7211, "Agregados para concreto: especificação", ABNT, Rio Janeiro (2019).

[14] NBR NM 45, "Agregados: determinação da massa unitária e do volume de vazios", ABNT, Rio Janeiro (2006).

[15] NBR NM 52, "Agregado miúdo: determinação de massa específica e massa específica aparente", ABNT, Rio Janeiro (2009).

[16] NBR NM 30, “Agregado miúdo: determinação da absorção de água”, ABNT, Rio Janeiro (2001).

[17] NBR 7215, "Cimento Portland: determinação da resistência à compressão", ABNT, Rio Janeiro (2019).

[18] NBR 13278, "Argamassas para assentamento e revestimento de tetos: determinação da densidade de massa e do teor de ar incorporado", ABNT, Rio Janeiro (2005).

[19] NBR 9778, "Argamassa e concreto endurecidos: determinação da absorção de água, índice de vazios e massa específica", ABNT, Rio Janeiro (2009).

[20] NBR 15261, “Argamassas para assentamento e revestimento de paredes e tetos: determinação da variação dimensional (retração linear)", ABNT, Rio Janeiro (2005).

[21] A.E.B. Cabral, V. Schalch, D. Molin, Ibracon Struct. Mater. J.3 (2010) 1.

[22] P. Saiz Martínez, M. González Cortina, F. Fernández Martínez, A. Rodríguez Sánchez, J. Clean. Prod. 118 (2016) 162.

[23] J.R. Jiménez, J. Ayuso, A.P. Galvín, M. López, F. Agrela, Constr. Build. Mater. 34 (2012) 34.

[24] J. Silva, J. de Brito, R. Veiga, Constr. Build. Mater. 23 (2009) 556.

[25] L.F.R. Miranda, C.S. Constantino, C.R. Monich, A.A.M. Neto, J. Mater. Civ. Eng. 25 (2013) 236.

[26] R.V. Silva, J. De Brito, R.K. Dhir, Constr. Build. Mater. 105 (2016) 400.

[27] E.F. Ledesma, J.R. Jiménez, J. Ayuso, J.M. Fernández, J. De Brito, J. Clean. Prod. 87 (2015) 692.

[28] C. Muñoz-Ruiperez, A. Rodríguez, S. Gutiérrez-González, V. Calderón, Constr. Build. Mater. 118 (2016) 139.

[29] R. Raeis Samiei, B. Daniotti, R. Pelosato, G. Dotelli, Constr. Build. Mater. 84 (2015) 84.

[30] P. Saiz-Martínez, M. González-Cortina, F. FernándezMartínez, Mater. Constr. 65,319 (2015) 1.

[31] H. Carasek, A.C.C. Girardi, R.C. Araújo, R. Angelim, O. Cascudo, Cerâmica 64, 370 (2018) 288.

[32] Z.H. Duan, C.S. Poon, Mater. Des. 58 (2014) 19.

(Rec. 16/06/2020, Rev. 25/11/2020, Ac. 10/02/2021) 